\title{
Analysis of Circulating Immune Complexes and Detection of Microbial Antigenic Components in Breast Tumours in Anambra State Nigeria
}

\author{
Michael Chukwudi Ezeani, ${ }^{1, *}$, Charles Chinedum Onyenekwe ${ }^{2}$, Samual Chukwuemeka Meludu $^{3}$, \\ Gabriel Udeze Chianakwana ${ }^{4}$, Daniel Chukwuemeka Anyiam ${ }^{5}$, Comfort Nne Akujobi, \\ Chiemelu Dickson Emegoakor ${ }^{4}$, Martin Ositadimma Ifeanyichukwu ${ }^{2}$, Ujuamala Uloma Ezeani ${ }^{7}$, \\ Nnadozi Okwudili Josiah ${ }^{8}$, Obi Ejeatuluchkwu', Jonathan Madukwe ${ }^{10}$ \\ ${ }^{1}$ Department of Immunology, Faculty of Medicine, Nnamdi Azikiwe University, Awka, Nigeria \\ ${ }^{2}$ Department of Medical Laboratory Science, Faculty of Health Science and Technology, Nnamdi Azikiwe University, Awka, Nigeria \\ ${ }^{3}$ Department of Human Biochemistry, Faculty of Basic Medical Sciences, Nnamdi Azikiwe University, Awka, Nigeria \\ ${ }^{4}$ Department of Surgery, Faculty of Medicine, Nnamdi Azikiwe University, Awka, Nigeria \\ ${ }^{5}$ Histopathology Department, Faculty of Medicine, Nnamdi Azikiwe University, Awka, Nigeria \\ ${ }^{6}$ Department of Medical Microbiology/Parasitology, Faculty of Medicine, Nnamdi Azikiwe University, Awka, Nigeria \\ ${ }^{7}$ Medical Centre, Pharmaceutical Unit, Nnamdi Azikiwe University, Nnewi Campus, Nigeria \\ ${ }^{8}$ Department of Chemical Pathology, Medical Laboratory Section, Nnamdi Azikiwe University Teaching Hospital, Nnewi, Nigeria \\ ${ }^{9}$ Pharmacology Department, Faculty of Medicine, Nnamdi Azikiwe University Awka, Nigeria \\ ${ }^{10}$ Histopathology Department, National Hospital, Abuja, Nigeria
}

\section{Email address:}

mikezeani@yahoo.com (M. C. Ezeani),mc.ezeani@unizik.edu.ng (M. C. Ezeani), cc.onyenekwe@unizik.edu.ng (C. C. Onyenekwe), sc.meludu@unizik.edu.ng (S. C. Meludu), gu.chianakwana@unizik.edu.ng (G. U. Chianakwana), dc.anyiam@unizik.edu.ng (D. Anyiam), cn.akujobi@unizik.edu.ng (C. N. Akujobi), drchinemelum@yahoo.com (C. D. Emegoakor),

ositadinma@unizik.edu.ng (M. O. Ifeanyichukwu), ujuamala@yahoo.com (U. U. Ezeani), Okwu4good@yahoo.com (O. J Nnadozie), ejeatuluobi@yahoo.com (O. Ejeatuluchkwu),ujamadukwe@gmail.com (J. Madukwe)

${ }^{*}$ Corresponding author

\section{To cite this article:}

Michael Chukwudi Ezeani, Charles Chinedum Onyenekwe, Samual Chukwuemeka Meludu, Gabriel Udeze Chianakwana, Daniel Chukwuemeka Anyiam, Comfort Nne Akujobi, Chiemelu Dickson Emegoakor, Martin Ositadimma Ifeanyichukwu, Ujuamala Uloma Ezeani, Nnadozi Okwudili Josiah, Obi Ejeatuluchkwu, Jonathan Madukwe. Analysis of Circulating Immune Complexes and Detection of Microbial Antigenic Components in Breast Tumours in Anambra State Nigeria. Cancer Research Journal. Vol. 5, No. 1, 2017, pp. 1-8.

doi: $10.11648 /$ j.crj.20170501.11

Received: December 13, 2016; Accepted: December 27, 2016; Published: January 25, 2017

\begin{abstract}
Quantitative measurement of circulating immune complexes in cancer patients is a widely accepted measure linking immune complexes as useful for treatment monitoring. However, the components of these immune complexes are generally understudied. By the analysis of immune complexes, this work elicited some microbial agents that could be associated with breast tumours. Total of 99 female subjects were randomly recruited for this study, of which 24 had benign tumour, 25 had malignant tumour and 50 were tumour free controls subjects. The mean age of the female subjects with benign breast tumour was $37.9 \pm 10.1$ years; malignant $49.6 \pm 10.8$ and control subjects $35.9 \pm 9.0$, and they were confirmed free from chemotherapy, autoimmune diseases and HIV infection. Immune complexes were precipitated and dissociated. Characterization of the antigens/antibodies was done using Enzyme linked immunoassay technique. Microbial antigenic components were detected in 21 benign tumour subjects, 20 malignant tumour subjects and 11 control subjects. Homogeneity and heterogeneity patterns of microbial antigenic distribution were seen in different groups. Heterogeneity pattern was prevalent in subjects with tumours. Detection of HCV was significantly high in subjects with benign and malignant tumours, while presence of Plasmodium falciparum, Helicobacter pylori and Salmonella typhi was also
\end{abstract}


prominent. HBV and treponema pallidum were implicated. Heterogeneity pattern was prevalent in late stages of breast cancer while Plasmodium falciparum, HCV and Salmonella typhi were most prominent. The burden of microbial infection is prevalent in breast tumour subjects. Presence of the microbial antigens would represent the burden of the microbial infection in tumour development and the consequences of the persistent circulation of these microbial proteins were discussed.

Keywords: Circulating Immune Complexes, Breast Tumourigenesis, Microbial Agents, Antigenic Components

\section{Introduction}

Tremendous progress has been made over the last decades in understanding the biology of breast cancer, however the mechanism for growth and progression of breast cancer with acquisition of invasive and metastatic phenotypes and therapeutic resistance are still not fully understood [1]. It is crucial to understand how these sporadic breast cancers arise in order to develop preventative strategies against this devastating disease [2]. Research has shown a steady rise in breast cancer cases in Nigeria [3]. This is an indication of inadequate or ineffective control measures to curtail the disease or due to diversion of global attention to HIV/AIDS (Human immune-deficiency virus/Acquired immune deficiency syndrome) and tuberculosis in the country [3]. Long-term exposure to extrinsic or environmental factors has been attributed for more than $70 \%$ of sporadic breast cancers [4]. Initially, research has shown that cancers are primarily an environmental disease with $90-95 \%$ of cases attributed to environmental factors and $5-10 \%$ due to genetics [5]. The sources of antigenic components of circulating immune complexes may be exogenous such as pathogen associated molecular pattern (PAMP), or endogenous such as damage associated molecular pattern (DAMP) resulted from "dangerous" entities including pathogens as well as injured, infected, diseased and necrotic tissues, or cells undergoing non-physiological cell death which emit danger signals (or alarmins) with pro-inflammatory activity [6]. Thus, a further implication of circulating immune complex (CIC) in oncology, is timely. Not necessarily estimating the level of CIC in subjects with breast tumour as so many researchers have done, but eliciting the complex antigens and antibody that remained in circulation and implicating or exonerating them from tumourigenesis.

An immune complex, sometimes called an antigenantibody complex, is a molecule formed from the integral binding of an antibody to a soluble antigen and the processing of immune complexes (IC) is mediated by complement and Fc $\gamma$ receptors [7]. Immune complexes have been shown to trigger a lot of immunological responses and are normally removed effectively by the mononuclear phagocytic system (MPS), thus are not detectable in the system and abnormalities in the processing of IC may result in their persistence and deposition outside the MPS, causing inflammation and tissue damage [8]. Abnormal immune complexes (IC) clearance has been implicated in the pathogenesis of autoimmune diseases, such as systemic lupus erythematosus [8]. There possible persistence in known pathological subjects such as subjects with benign and malignant tumour in highly environmentally polluted areas, calls for the need for their further evaluation. Research has shown that detectable levels of immune complexes are found in chronic or persistent exposure to foreign substances or ongoing infection [8]. Therefore, the persistence of IC might be a marker of ongoing or persisting infection. Thus we hypothesize that if this becomes an ongoing process, due to regular intake or regular exposure to fuelling factors, specific symptoms may occur and become chronic, depending on which organ has fixed the immune-complex.

It is known already that certain microorganisms are associated with the development of cancer. The microflora changes during cancer development are described in several studies and their role is suggested as a possible etiologic factor and potential diagnostic markers for cancer $[9,10]$. It is estimated that nearly $20 \%$ of all fatal cancers are due to microbial etiology, giving an indication toward substantial microbial involvement in carcinogenesis [11]. In addition to a microbial role in oncogenesis, the development of infectious complications in cancer patients is a major cause of morbidity and mortality. It is estimated that $60 \%$ deaths in patients with haematological malignancies are due to infectious complications [11]. However, the data with solid organ tumours are not extensively available, but it is estimated that infections are either primary or an associated reason for deaths in $50 \%$ solid organ tumours patients [12]. Besides reasons for the poor prognosis in breast cancer cases in developing countries like Nigeria where larger population are vulnerable to infection [13], have not been exposed, moreover analysis of circulating immune complexes could be a means of isolating microbial left over antigens in systemic circulation and as such an easier and better detective approach to microbial infection as some of the microbes are not easily isolated with artificial medium.

In this study, the analysis of immune complexes is done to indicate the presence of microbial antigenic components by dissociating the immune complexes to characterize microbial antigenic components and detect possible microbial agents prevalent in benign and malignant subjects compared to healthy control subjects. Some of the targeted microbial antigenic components belong to: Hepatitis $C$ virus, Plasmodium falciparum, Hepatitis B virus, Salmonella spp, Helicobacter pylori, Treponema pallidum, Mcobacterium tuberculosis. It should be noted that the immune complexes formed due to the presence of these microbial antigens, are in circulation thus capable of reaching and depositing in any 
part of the body including the breast.

\section{Materials and Methods}

\subsection{The Subjects}

The subjects were grouped into three; they include 24 female subjects with benign breast tumour, 25 female subjects with malignant breast tumour (Cancer subjects) and 50 female subjects without breast tumour (Healthy Subjects). The benign and malignant breast tumour subjects were attending clinic at the surgical unit of Nnamdi Azikiwe University Teaching Hospital Nnewi, Anambra State, Nigeria. The 50 healthy subjects were volunteers who were clinically confirmed free from breast tumour. None of the subjects had received any breast tumour chemotherapy prior to the study. All the subjects were screened clinically and biochemically to exclude any autoimmune diseases and Human Immunodeficiency Virus. Oral informed consent was obtained from the subjects before participation. All the subjects were orally interviewed (administered questionnaire) to obtain medical history and demographic information.

\subsection{Cancer Diagnosis and Staging}

The diagnosis of breast tumour was established by histopathological examination of biopsy and detection of cancer associated antigen 15-3 (CA 15-3), while the staging of cancer was done according to the American Joint Committee for Cancer (TNM classification).

\subsection{Specimen Collection}

Up to $10 \mathrm{ml}$ of blood samples were drawn by veni-puncture from 50 healthy subjects. Approximately $10 \mathrm{ml}$ of blood was collected by veno-puncture from the breast tumour subjects. Up to $1 \mathrm{ml}$ of blood was put in an EDTA Ethylenediaminetetraacetic acid container for Plasmodium falciparum detection, while the remaining $9 \mathrm{ml}$ was put in a plain vacutainer tube. The blood samples were allowed to clot at room temperature for 30 minutes. The retracted clot was removed by centrifugation (Sorvall RC5C HS-4 rotor at $1500 \mathrm{x} \mathrm{g}$ for $15 \mathrm{~min})$ at room temperature $\left(26^{\circ} \mathrm{C}\right)$. Immune complex precipitation was carried out immediately. Other Sera were stored in aliquots at $-20^{\circ} \mathrm{C}$.

\subsection{Immune Complex Precipitation and Estimation}

The polyethylene glycol (PEG) method was used to precipitate immune complexes [8]. Approximately $0.2 \mathrm{ml} \mathrm{(1}$ part) of the freshly obtained serum was mixed with $0.4 \mathrm{ml}(2$ parts) of $0.01 \mathrm{M}$-borate buffer, $\mathrm{pH} 8.4$. To this mixture, 27 parts of $4.166 \%$ PEG (polyethylene glycol: average molecular weight, 6,000; Sigma)) was added (final 1:30 serum dilution and $3.75 \%$ PEG concentration was obtained). The mixture was incubated at room temperature for 60 minutes; the turbidity developed was measured spectrophotometrically at $450 \mathrm{~nm}$ against control containing 1:30 diluted serum in borate buffer without PEG. The level of CIC in serum was expressed in terms of OD450 measured at the end of 60 minutes. The result was expressed as Peg Index derived by the formula: Peg Index= OD450 with Peg OD450 with Borate Buffer Solution without PEG, x 1000 [8].

\subsection{Immune Complex Dissociation}

Up to $1 \mathrm{ml}$ of $4 \%$ PEG (average molecular weight, 6,000; Sigma) and $0.44 \%$ Sodium chloride in $0.1 \mathrm{M}$ borate buffer $(\mathrm{pH}$ 8.4) was added drop wise with constant stirring to $1 \mathrm{ml}$ of serum in a micro-centrifuge tube (Eppendorf). Tubes were vortexed, left at $4{ }^{\circ} \mathrm{C}$ for at least 3 hours and centrifuged at $10,000 \mathrm{rpm}$ ( (Sorvall RC5C HS-4 rotor 8,320 $\times \mathrm{g}$ ) for $15 \mathrm{~min}$ in the cold. Supernatants were carefully removed with a pipette. The pellet was re-suspended and washed twice with $2 \mathrm{ml}$ of $2 \%$ PEG solution in the same buffer, removing the supernatant carefully each time by means of aspiration using Pasture pipette. After the second spin, samples were re-suspended in $2 \mathrm{ml}$ of $0.1 \mathrm{M}$ sodium borate buffer, $\mathrm{pH}$ 10.2. Dissociated ICs were kept in buffer at $4^{\circ} \mathrm{C}$ until use. There was no discernible loss of reactivity after 1 month of storage [13]. The dissociated immune complex solution was assayed serologically for Salmonella typhi antigens, Malaria parasites (Plasmodium falciparum), Hepatitis $B$ surface antigen (HbsAg), Hepatitis $C$ virus ( $\mathrm{HCV})$, Mycobacterium tuberculosis antibodies, Helicobacter pylori antibodies and Treponema pallidum, using specific enzyme immune-assay kit [13].

\subsection{Exclusion Criteria}

Subjects with Human Immunodeficiency Virus /Acquired Immune Deficiency Syndrome Subjects with positive rheumatoid Factor tests and tumour subjects under chemotherapy or had under gone surgical operation

\subsection{Inclusion Criteria}

The subjects presented with benign and malignant breast tumour.

\subsection{Ethical Approval}

Approval for the study was obtained from the ethics committee of Nnamdi Azikiwe University Teaching Hospital Nnewi Anambra State Nigeria.

\subsection{Statistical Analysis}

Statistical Package for Social Sciences (SPSS), was used for statistical analysis. Descriptive statistics was done to detect the frequency of occurrences while Chi-square was used to determine the significant levels of microbial involvement. Pvalues $<0.05$ was considered statistically significant.

\section{Results}

\subsection{Percentage Distribution of Subjects with and Without Evidence of Microbial Antigenic Components}

By characterization of antigenic components of circulating 
immune complexes, microbial antigens were detected in 21 $(87 \%)$ benign subjects; $20(80 \%)$ malignant subjects and 9 $(27.3 \%)$ breast tumour free control subject. Those free from microbial antigenic components were $3(12 \%)$ of the benign subjects; 5 (20\%) of the malignant subjects and $24(72.7 \%)$ of the control subjects (Table 1).

\subsection{Percentage Distribution of Microbial Antigenic Components in Different Stages of Breast Cancer}

The staging of the malignancy done according to the American Joint Committee on Cancer (2010), revealed that out of the 25 subjects with malignant tumour, $5(20 \%)$ were at stage $2 \mathrm{~b}, 9(36 \%)$ were at stage $3 \mathrm{~b}, 7(28 \%)$ were at stage $3 \mathrm{c}$ while $4(16 \%)$ were at stage 4 . Out of 5 subjects with malignant breast tumour in stage $2 \mathrm{~b}, 4$ (80\%) had CIC with microbial antigenic component (MAC) while 1 (20\%) had CIC without a microbial antigenic component. Prevailing number of malignant subjects with MAC was detected in stage $3 \mathrm{~b}$ and 3 totalling 9 subjects. Out of these 9 subjects, 7 (77.8\%) had CIC with MAC while 2 (22.2) had CICs without MAC. Stage $3 c$ had 7 subjects and all the 7 (100\%) subjects had microbial antigenic components (MACs) while stage 4 had 4 subjects $3(75 \%)$ of the subjects had CIC with MACs while 1 (25\%) had CIC without a MAC (Table 2).

\subsection{Percentage Distribution of Microbial Agentsbythe Analysis of Immune Complexes in Various Stages of Breast Cancer}

Based on the analysis of antigenic components of circulating immune complexes, the result showed that in stages 3b, and 3c, Malaria parasite (Plasmodium falciparum) was detected in $5(55.6 \%)$ and $5(71.4 \%)$ respectively, but was not detected in subjects in stages $2 \mathrm{~b}$ and 4. Treponema pallidum was detected in $1(20 \%)$ of the 5 subjects in stage $2 \mathrm{~b}$ and $1(14.3 \%) 3 \mathrm{c}$ respectively, but was not detected in stages $3 \mathrm{~b}$ and 4 . Hepatitis B. Virus was detected in $1(11.1 \%)$ of the 9 subjects in stage $3 \mathrm{~b}, 1$ $(14.3 \%)$ of the 7 subjects in stage $3 \mathrm{c}$, but was not detected in stages $2 \mathrm{~b}$ and 4. Hepatitis C. Virus was detected in 3
$(33.3 \%)$ of the 9 subjects in stage $3 b, 2$ (28.6\%) of the 7 subjects in stage $3 \mathrm{c}$ and $2(50 \%)$ of the 4 subjects in stage 4 , but was not found in stage 2. Helicobacter pylori was detected in $1(20 \%)$ of the 5 subjects in stage 2 b, $1(11.1 \%)$ of the 9 subjects in stage $3 \mathrm{~b}, 2(28.6 \%)$ of the 7 subjects in stage $3 \mathrm{c}$ and $1(25 \%)$ of the 4 subjects in stage 4 . Mycobacterium tuberculosis was not detected in any of the stages. Salmonella typhi was detected in $1(20 \%)$ of the 5 subjects in stage $2 \mathrm{~b}, 1(11.1 \%)$ of the 9 subjects in stage $3 \mathrm{~b}$, $4(57.1 \%)$ of the 7 subjects in stage $3 c$ and $2(50 \%)$ of the 4 subjects in stage 4 .

\subsection{Distribution of Microbial Agents by the Analysis of Immune Complexes in Subjects with Breast Tumours}

Based on the analysis of antigenic components of circulating immune complexes, the statistics showed that distribution of malaria parasites (Plasmodium falciparum) in subjects with benign breast tumour $11(45.8 \%)$; subjects with malignant breast tumour $10(40 \%)$; control subjects 12 (24\%) was not significantly different $\mathrm{P}=0.913$. Distribution of Hepatitis $\mathrm{C}$ virus (HCV) in subjects with benign breast tumour $10(41.7 \%)$; subjects with malignant breast tumour 7 (28\%); control 1 (2\%) was significantly different $\mathrm{P}=0.030$. The frequency distribution of Helicobacter pylori in subjects with benign breast tumour $8(33.3 \%)$; subjects with malignant breast tumour $5(20 \%)$; control $0(0 \%)$, was not significantly different $\mathrm{P}=0.405$. The frequency distribution of Salmonella typhi in subjects with benign breast tumour $5(20.8 \%)$; subjects with malignant breast tumour $8(32 \%)$ and control subjects $0(0 \%)$, was not significantly different $\mathrm{P}=0.405$. The frequency distribution of Hepatitis $B$ virus in subjects with benign breast tumour 2 $(8.3 \%)$; subjects with malignant breast tumour $2(8 \%)$ and control subjects $0(0 \%)$ was not significantly different $\mathrm{P}=0.1000$. The frequency distribution of Treponema pallidum in subjects with benign breast tumour $1(4.2 \%)$; subjects with malignant breast tumour $2(8 \%)$ and control subjects $0(0 \%)$ was not significantly different $\mathrm{P}=0.564$. Only one subject with a benign tumour was found to harbor Mycobacterium tuberculosis (Table 4).

Table 1. PercentageDistributionofSubjectswithandwithoutEvidenceofMicrobialAntigenic.

\begin{tabular}{llll}
\hline & $\begin{array}{l}\text { Benign } \\
\mathbf{N = 2 4}\end{array}$ & $\begin{array}{l}\text { Malignant } \\
\text { N=25 }\end{array}$ & \multicolumn{1}{c}{$\begin{array}{l}\text { Control } \\
\text { N=50 }\end{array}$} \\
\hline MAC Present & $21(87.5 \%)$ & $20(80 \%)$ & $11(22 \%)$ \\
MAC Absence & $3(12.5 \%)$ & $5(20 \%)$ & $39(78 \%)$ \\
\hline
\end{tabular}

MAC: Microbial Antigenic Component

Table 2. Percentage Distribution of Microbial Antigenic Components in Different Stages of Breast Cancer.

\begin{tabular}{|c|c|c|c|c|}
\hline & $\begin{array}{l}\text { Stage } 2 b \\
\mathrm{~N}=5\end{array}$ & $\begin{array}{l}\text { Stage } 3 b \\
N=9\end{array}$ & $\begin{array}{l}\text { Stage 3c } \\
\mathrm{N}=7\end{array}$ & $\begin{array}{l}\text { Stage } 4 \\
\mathrm{~N}=4\end{array}$ \\
\hline Presence of Microbial Antigenic Component & $4(80 \%)$ & $7(77.7 \%$ & $7(100 \%)$ & $3(75 \%)$ \\
\hline Absence of Microbial Antigenic Component & $1(20 \%)$ & $2(22.2 \%)$ & $0(0 \%)$ & $1(25 \%)$ \\
\hline
\end{tabular}


Table 3. Percentage Distribution of Microbial Agents by the Analysis of Immune Complexes in Various Stages of Breast Cancer.

\begin{tabular}{|c|c|c|c|c|}
\hline & $\begin{array}{l}\text { Stage 2b } \\
N=5\end{array}$ & $\begin{array}{l}\text { Stage 3b } \\
\mathbf{N}=9\end{array}$ & $\begin{array}{l}\text { Stage 3c } \\
N=7\end{array}$ & $\begin{array}{l}\text { Stage } 4 \\
\mathrm{~N}=4\end{array}$ \\
\hline \multirow{2}{*}{ MP (Pf) } & & $* 1 / / * * 4$ & $* * 5$ & \\
\hline & $0(0 \%)$ & $5(55.6 \%)$ & $5(71.4 \%)$ & $0(0 \%)$ \\
\hline \multirow{2}{*}{ T. pallidum } & $* 1$ & & $* 1$ & \\
\hline & $1(20 \%)$ & $0(0 \%)$ & $1(14.3 \%)$ & $0(0 \%)$ \\
\hline \multirow{2}{*}{ HBV } & & $* * 1$ & $* * 1$ & \\
\hline & $(() \%)$ & $1(11.1 \%)$ & $1(14.3 \%)$ & $0(0 \%)$ \\
\hline \multirow{2}{*}{$\mathrm{HCV}$} & & $* 1 / / * * 2$ & $* 1 / / * * 1$ & $* * 2$ \\
\hline & $0(0 \%)$ & $3(33.3 \%)$ & $2(28.6 \%)$ & $2(50 \%)$ \\
\hline \multirow{2}{*}{ H.pylori } & $* 1$ & $* * 1$ & $* 1 * * 1$ & $* * 1$ \\
\hline & $1(20 \%)$ & $1(11.1 \%)$ & $2(28.6 \%)$ & $1(25 \%)$ \\
\hline TB & $0(0 \%)$ & $0(0 \%)$ & $0(0 \%)$ & $0(0 \%)$ \\
\hline \multirow{2}{*}{ Samonella spp } & & $* * 1$ & $* * 4$ & $* * 2$ \\
\hline & $1(20 \%)$ & $1(11.1 \%)$ & $4(57.1 \%)$ & $2(50 \%)$ \\
\hline
\end{tabular}

**Number of individuals with heterogeneity of microbial antigenic components

*Number of individual with homogeneity of microbial antigenic components MP $(\mathrm{Pf})=$ Malaria parasite (Plasmodium falciparum)

T.pallidum $=$ Treponema pallidum; $\mathrm{TB}(\mathrm{Mt})=$ Tuberculosis $($ Mycobacterium tuberculosis)

$\mathrm{HBV}=$ Hepatitis $B$ virus; $\mathrm{HCV}=$ Hepatitis $\mathrm{C}$ virus; H.pylori $=$ Helicobacter pylori

Table 4. Percentage Distribution of Microbial Agents by the Analysis of Immune Complexes in Subjects with Breast Tumours.

\begin{tabular}{|c|c|c|c|c|}
\hline & $\begin{array}{l}\text { Benign } \\
\mathrm{N}=\mathbf{2 4}\end{array}$ & $\begin{array}{l}\text { Malignant } \\
\mathrm{N}=25\end{array}$ & $\begin{array}{l}\text { Control } \\
\mathrm{N}=50\end{array}$ & P-Value \\
\hline \multirow{2}{*}{ MP (Pf) } & $* * 8 / / * 3$ & $* * 9 / / * 1$ & $* 11 / / * * 1$ & \\
\hline & $11(45.8 \%)$ & $10(40 \%)$ & $12(24 \%)$ & 0.913 \\
\hline \multirow{2}{*}{$\mathrm{HCV}$} & $* * 8 / / * 2$ & $* * 5 / / * 2$ & $* * 1$ & \\
\hline & $10(41.6 \%)$ & $7(28 \%)$ & $1(2 \%)$ & 0.030 \\
\hline \multirow{2}{*}{ H.pylori } & $* * 5 / / * 3$ & $* * 3 / / * 2$ & & \\
\hline & $8(33.3 \%)$ & $5(20 \%)$ & $0(0 \%)$ & 0.405 \\
\hline \multirow{2}{*}{$\begin{array}{l}\text { Samonella } \\
\text { typhi }\end{array}$} & $* * 3 / / * 2$ & $* * 7 / / * 1$ & & \\
\hline & $\begin{array}{l}5(20.8 \%) \\
* * 2\end{array}$ & $\begin{array}{l}8(32 \%) \\
* * 2\end{array}$ & $0(0 \%)$ & 0.405 \\
\hline HBV & $2(8.3 \%)$ & $2(8 \%)$ & $0(0 \%)$ & 0.1000 \\
\hline T.pallidum & *1 $1(4.2 \%)$ & $\begin{array}{l}* 2 \\
2(8 \%)\end{array}$ & $0(0 \%)$ & 0.564 \\
\hline Mtb & & $0(0 \%)$ & $0(0 \%)$ & 1.000 \\
\hline
\end{tabular}

KEY: **Number of individuals with heterogeneity of microbial antigenic components

*Number of individual with homogeneity of microbial antigenic components

\section{Discussion}

Many research works earlier done on immune complexes, bordered on quantification of immune complexes in cancer patients $[14,15]$. However, this study ventured into the specific detection of presence of microbial proteins that have been complexed with antibody and remain in circulation. The consequence of this is presumed to be enablement of immunopathologically mediated tumorigenesis or tumour metastasis via sustenance of chronic inflammation. The quantitative analysis of CIC in previous studies could not indicate the peculiar influence CIC may have in tumourigenesis instead they were used to monitor progress of cancer treatments. This is the first work indicting microbial agent in breast tumour through the analysis of circulating immune complexes. This is beyond what microbiological culture would have done because these antigens may continue in circulation without the presence of the microbial organism proper. The importance of this analysis should not be over emphasized considering the fact that some individuals are continually exposed in highly polluted environment including individual attitudes to hygiene, nature of work and sexual life and as such renders them vulnerable to persistent infections [13]. Previous studies have shown that infectious complications are a serious cause of morbidity and mortality in cancerpatients, especially those with underlying hematological malignancies whereautopsy studies demonstrate that approximately $60 \%$ of deaths are infectionrelated [16]. Although there is paucity of data on infectious mortality in patients with solid organ tumors, approximately $50 \%$ of these patients are estimated to have an infection as either the primary or an associated cause of death [16]. Factors that predispose to infection are divided into those that are host associated and those that are treatment associated. Host-associated factors include underlying immune deficiencies, medical comorbidities, past infections, poor nutritional status, and psychological stress. Treatment-associated factors include surgery, radiation, immunosuppressant therapies, antimicrobial use, and invasive procedures [17].

Several bacterial infections have been shown to serve as a risk factor for development of cancer at various sites [18]. The extreme scientific interest is focused on the role of infection-inflammation in the initiation and progression of cancer, in which case persistence of microbial protein (bound or free) would induce persistent cell activation $[19,20]$. The persistent cell activation in the context of chronic infection might promote cell transformation via DNA damage or production of pro-inflammatory factors that sustain chronic inflammation and may support tumour growth [21]. Considerably, dealing with microbial antigens in this study may not justify the role a fully fledged microbial agent may play in the infected system. However, while the presence of a microbial agent would mediate patho-physiological damages, the retention of their antigens would mediate immunepathological consequences as well as fuel chronicity. The presence of microbial antigenic components (MACs) or its absence in immune complex can induce enzymatic/chemical hydrolysis of DNA by activation and persistent stimulation of immune cells and molecular pathways. This can be squealed to an earlier research report, that the first step in any epigenetic study is global DNA methylation analyses which rely mostly on a prior enzymatic/chemical hydrolysis of DNA to obtain 2'-deoxymononucleosides [22].

The preponderant majority of benign $(87.5 \%)$ and malignant $(80 \%)$ breast tumour subjects harbour microbial antigenic components in lieu of other antigenic components (benign $12.5 \%$ and malignant $20 \%$ ), this was found not to be a normal setting based on the findings that healthy control counterparts harbour significant low levels of microbial antigenic components. This work has revealed that microbial antigens are prevalent in breast tumours in this locality. The consequences of these persistent circulations of CICs have 
been addressed above.

Notable microbial agents detected in this study through the analysis of components of the immune complex, include: Plasmodium falciparum, Treponema pallidum, Hepatitis $B$ virus, Hepatitis $C$ virus, Helicobacter pylori and Salmonella typhi. Previous researches have implicated Helicobacter pylori, Streptococcus bovis, Chlamydia pneumoniae, Campylobacter rectus, Epstein-Barr virus, hepatitis viruses, Human papilloma virus, polyomaviruses, etc.), to contribute to the host epigenetic changes resulting in the onset and progression of some diseases, especially in malignancies [23]. Further detailed analysis of this work, singled out those subjects with only a particular bound microbial antigen, referred to as homogeneity of microbial antigenic component of immune complexes. This pattern of antigenic retention was found to be prevailing in healthy subjects, with respect to Plasmodium falciparum infection. On the other hand, mixed microbial antigens referred to as heterogeneity of microbial antigens, was also detected which prevalence was significantly greater in subjects with breast tumour. This is a clear indication that microbial infection could be significantly influential in tumour development or progression. We also infer that retention of these microbial antigens could be an influential source of persistent inflammatory response. The mechanisms of inflammation, by immune complex, resulting from bacteria and other related agents have been revealed [24]. The immune system which recognizes antigens or cell damage, activates an influx of neutrophil and macrophages that take up the bacteria, dead cells and debris which include proteins nucleic acid and other molecules released by the damaged cells. In response, the cells release highly reactive chemicals such as reactive oxygen species (ROS) that mediate degradation of the bacteria as well as diffuse into the tissue and may cause its injury [24]. The persistence of such activities we inferred would sustain chronic inflammation which may provide an appropriate microenvironment for the transformation of cells by insertion of oncogenes and inhibition of tumour suppressor genes leading to initial tumour development. The prostaglandins, reactive oxygen species (ROS), Nitrogen species, Micro RNAs which are all key mediators of inflammatory induced cancer, may cause changes in cell proliferation, cell death, DNA methylation and DNA mutation that also contribute to carcinogenesis [25].

Unlike the immunosuppressive mechanism induced by $\mathrm{HIV}$, the mechanism by which Hepatitis $\mathrm{B}$ and $\mathrm{C}$ viruses contribute to cancer still remains obscure. HBV and HCV are both hepatotropic viruses. Their co-infection is associated with clinically and histologically more severe liver disease and higher risk of the development of hepatocellular carcinoma [26, 27]. However, HCV infection has been reported to predispose patients to extrahepatic disorders involving renal, dermatologic, hematologic, and rheumatologic systems as well as autoimmune abnormalities [27]. Extrahepatic manifestations may result from immunologically triggered mechanisms as well as virus invasion and replication that affect extrahepatic tissues and organs. Only $\mathrm{HCV}$ has the lymphotropic character that is assumed to be the cause of $\mathrm{HCV}$-associated extrahepatic manifestation. This may justify the importance of analysing circulating immune complexes and characterization of their antigenic components owing to the fact that such antigens may leave the hepatic site and remain in circulation and eventually deposit in breast tissues or any other organs.

Research has shown that HCV, but not HBV, was associated with breast cancer [27]. This present study upholds this report to a certain extent but differs as well. This is because the rate of occurrence of $\mathrm{HCV}$ was very high. However, detection of $\mathrm{HBV}$ in subjects with benign and malignant tumours in this study suggests that HBV may also be implicated in breast tumour and thus deviates at this point with the report of [27]. The diagnostic approach may also contribute to the differences in the results. Thus the use of dissociated antigen-antibody complex as embraced in this study, is a rare approach but has proven reliable in microbial detection where microbial agent could not be isolated or the antigen opsonised [8].

Tumor node metastasis (TNM) which is a measure of the stages of cancer has been used to measure cancer spread and prognosis [28], and is commonly used in the clinical setting. The stages range from 0 to IV, with stage 0 being in situ, stage I being early stage invasive cancer, and stage IV refers to the most advanced disease. Larger size, nodal spread, and metastasis have a larger stage number and a worse prognosis [29]. Stage 0 is a pre-cancerous or marker condition, either ductal carcinoma in situ (DCIS) or lobular carcinoma in situ (LCIS). Stages 1-3 are within the breast or regional lymph nodes. Stage 4 is 'metastatic' cancer that has a less favorable prognosis [28]. In this study, cancer patients were of 4 different stages of cancer $2 b, 3 b, 3 c$ and 4 . This indicated that the majority of the breast cancer cases did not present themselves for medical attention at the earlier stage. In this study, presence of microbial antigenic components was significantly higher than its absence in all stages of breast cancer, and the burden seem to be more in subjects in stages $3 \mathrm{~b}$ and $3 \mathrm{c}$. This indicates notable persistence of these microbial antigens in malignancy and could be contributing to escalation of the disease condition. Homogeneity of microbial antigenic distribution was prevalent in stage $2 \mathrm{~b}$. On the other hand, heterogeneity of microbial antigenic components was prevalent in stage $3 c$, followed by stages $3 b$ and 4 , with mixed infection of Plasmodium falciparum/HCV/Salmonella typhi and $\mathrm{HCV} /$ Salmonella typhi, leading the course of presentation. No heterogeneity of microbial antigenic circulation was found in stage $2 b$. Suffice it to say that mixed microbial infection is an important pathological phenomenon in breast cancer progression and metastasis.

These observations are easily linked with outlined central principles earlier reported, that although the microbial agents and tumours they promote are quite varied; several principles are conserved and can be used to guide future considerations [30]. First, oncogenic microbes generally persist in their hosts for long periods (years or longer). The mean duration of tumour presentation in subjects with benign tumour was 
$18.83 \pm 20.86$ and malignant tumour $36.19 \pm 53.0$ months. Acute infections may be resolved but also may leave scars that promote neoplasia. This process seems to be exceptional, however. Much more common are persisting microbes that the host cannot eliminate and which engage the host in an ongoing battle that damages tissues [31] and promotes tumour formation and subsequent malignancy. This study has practicalised this theory by using the analysis of immune complexes to implicate microbial agents to tumourigenesis. Most of the microbial agents implicated are known for chronicity. It was also discovered in this study that one of the best approaches to studying persistent infection is through antigenic left over, bound by its corresponding antibody in the system. For example, squamous cell carcinomas follow the long-term inflammatory consequences of chronic osteomyelitis with sinus tract formation [31]. A group of colonizing organisms rather than a single pathogen has been recognized as provoking this chronic inflammation [31]. In this study, different microbial antigens were detected in many subjects in homogenous or heterogenous forms, with recorded persistent characters. Secondly, variation in oncogenic potential exists within microbial species. This variation has been well established for Papiloma virus (HPV), certain types of which cause most cancers, and for the hepatitis viruses and $H$. pylori, in which particular genotypes are most virulent [30]. Third, microbial load often matters. Fourth, the interactions between microbial genotype and load may be synergistic, leading to markedly enhanced disease risks [32]. Fifth, host genotypes and phenotypes (e.g., host age and age on acquiring an organism) are part of the microbial genotype-load interaction and modulate risk (33, 32). Sixth, because microbes are communicable agents, their prevalence in individuals in a prior generation influences their prevalence in the next. Therefore, secular trends toward intergenerational amplification (of prevalence or virulence) can develop in a population without any known increase in exposure, in contrast to chemical carcinogenesis, for example. As obligate intracellular parasites, viruses have developed numerous ways of hijacking cell processes to facilitate the completion of their life cycle and sometimes to evade the immune responses of their host. Viruses that cause persistent (often latent) infections are likely to benefit from heritable epigenetic changes in host transcription that produce an environment for their latent or persistent state without having to continuously express the initiating effectors [34]. Host genes involved in cell cycle progression, senescence, survival, inflammation and immunity are prime candidates as targets for such epigenetic control. Upon a microbial attack, host cells undergo massive changes in their transcriptional program, mobilizing genes involved in key processes (e.g, immunity, cell death/survival, and adhesion/motility) to trigger an appropriate response [35, 36]. It is thus not surprising that successful pathogens have developed specific mechanisms to deregulate the expression levels and/or kinetics of these defense genes. Host transcription factors are first obvious targets to reprogram the genome and bacteria use diverse tricks to alter their function.
For instance, bacterial factors can hijack cellular signalling pathways that activate or sequester transcription factors (e.g., NF- $\kappa$ B, IRF/STATs, or AP-1) in the cytosol of targeted cells, or manipulate their half-lives via posttranslational modifications [37, 38]. In this study, we infer that immune complexes can wholesomely be involved in tumourigenesis in this case breast tumourigenesis by retention of microbial antigens and as foreign subjects, would continue to alter the basic molecular make ups for normal haemostasis. Our emphasis is on microbial antigenic component of the immune complexes, which source is exogenous or environmental, emanating from infections due to microbial agents. We propose that these microbial antigens if eminent could contribute immensely to poor prognostic condition of breast cancer presentation in Nigeria and some other parts of developing countries as a result of its ability to fuel chronic inflammatory response.

\section{Conclusion}

Analysis of circulating immune complexes is important in accessing the burden of microbial infections even in subjects with breast tumours. Microbial agents are implicated in breast tumour. Microbial antigenic components could be a leading cause of poor prognosis trailing breast cancer cases in developing countries. The burden of microbial infection is prevalent in breast tumour subjects than the healthy control subjects and could enhance tumour progression and metastasis. Both $\mathrm{HCV}$ and $\mathrm{HBV}$ could contribute to microbial influences in breast tumourigenesis.

\section{Acknowledgement}

Our special appreciation goes to Professor C. Dioka the head of Chemical Pathology Department, Nnamdi Azikiwe University Teaching Hospital Nnewi, Nigeria, for providing the laboratory space used for this work.

\section{References}

[1] Prathap Kumar S. Mahalingaiah and Kamaleshwar P. Singh. Chronic Oxidative Stress Increases Growth and Tumorigenic Potential of MCF-7 Breast Cancer Cells. PLoS One. 2014; 9 (1): e87371.

[2] Xuan C, Jaime MS, Alice C. Microbial Dysbiosis Is Associated with Human Breast Cancer 2014; v PLoS One. 9, e83744.

[3] Elima Jedy-Agba, Maria Paula Curado, Olufemi Ogunbiyi et al. Cancer Epidemiology. 2012; 36 (5): e271-e278.

[4] Rathore K, Choudhary S, Odoi A, et al. Green tea catechin intervention of reactive oxygen species-mediated ERK pathway activation and chronically induced breast cell carcinogenesis. Carcinogenesis 2012; 33: 174-183

[5] Anand P, Kunnumakkara AB, Sundaram C, et al. Cancer is a preventable disease that requires major lifestyle changes. Pharmaceutical Research 2008; 25: 2097-2116. 
[6] Abhishek DG, Lorenzo G, Lionel A, et al. Molecular and Translational Classifications of DAMPs in Immunogenic Cell Death. Frontier Immunology 2015; doi.org/10.3389/fimmu.2015.00588

[7] Nash JT, Taylor PR, Botto $M$ et al. Immune complex processing in Clq-deficient mice. Clinical Experimental Immunology 2001; 123 (2): 196-202.

[8] Brunner M, and Sigal LH. Use of serum immune complexes in a new test that accurately confirms early Lyme disease and active infection with Borrelia burgdorferi. Journal Clinical Microbiology 2001; 39: 3213-3221.

[9] Bonnet M. Buc E, Sauvanet P et al. Colonization of the human gut by E. Coli and colorectal cancer risk. Clinical Cancer Research 2014; 20: 859-867.

[10] Khan AA, Shrivastava A, Khurshid M, et al. Normal to cancer microbiome transformation and its implication in cancer diagnosis. Biochimistry Biophysics Acta 2012; 1826: 331337.

[11] Reinwald M, Boch T, Hofmann W, et al., Risk of Infectious Complications in Hemato-Oncological Patients Treated with Kinase Inhibitors. Biomarker Insights 2015; 10 (Suppl 3): 5568 .

[12] Zembower TR. Epidemiology of Infections in Cancer Patients. Cancer treatment and research 2014; 161: 43-89

[13] MC Ezeani, MI Agba CC Onyenekwe, I Anahalu, CC Azikiwe, BE Unaeze $\mathrm{f}$, UU Ezeani Aerobacteriology of laboratories and offices: Evidence of high risk exposure to immune complex formation in Nigeria. Asian Pacific Journal of Tropical Disease 2011; 1 (2): 131-136.

[14] Parveen S, Neeraj T, Renuka JB, Deka AC. Evaluation of circulating immune complexes and serum immunoglobulins in oral cancer patients - A follow up study. Indian journal of dental research 2010; 21 (1): 10-125

[15] Rai S and Mody RN. Serum circulating immune complexes as prognostic indicators in premalignant and malignant lesions of oral cavity during and following radiotherapy 2012; 8 (6): 116-122

[16] Stosor V. and Zembower TR. Infectious Complications in Cancer Patients. Cancer Treatment and Research 161, DOI: 10.1007/978-3-319-04220-6_2,

[17] Donnelly JP, Blijlevens NMA, De Pauw BE. Infections in the immunocompromised host: general principles. In: Mandell GL, Bennett JE, Dolin R (eds) Mandell, Douglas, and Bennett's principles and practice of infectious diseases. Churchill Livingstone, Philadelphia, 2009; 3781-3792

[18] Blaser MJ, Kirschner. The equilibria that permit bacterial persistence in human hosts. Nature 2007; 449: 843-9.

[19] Balkwill F, Mantovani A, et al. "Inflammation and cancer: back to Virchow?" The Lancet 2001; 357: 539-545

[20] Johny E Elkahwaji The role of inflammatory mediators in the development of prostatic hyperplasia and prostate cancer. Research Reproduction Urology 2013; 5: 1-10.

[21] Dawit Kidane, Wook Jin Chae, Jennifer Czochor, Kristin A. Eckert, Peter M. Glazer, Alfred L. M. Bothwell, and Joann B. SweasyInterplay between DNA repair and inflammation, and the link to cancer. Critical Review Biochemistry Molecular
Biology 2014; 49 (2): 116-139.

[22] Chinnusamy V, Zhu JK. RNA-directed DNA methylation and demethylation in plants. Science in China. Series C, Life Science 2009; 52: 331-343.

[23] Gilbert SF, McDonald E, Boyle N, Buttino N, Gyi L, Mai M. Symbiosis as a source of selectable epigenetic variation: taking the heat for the big guy. Philosophical Transaction Royal Society 2010; 365: 671-678.

[24] Tanya N. Mayadas, George C. Tsokos and Naotake Tsuboi, Mechanisms of Immune Complex Mediated Neutrophil Recruitment and Tissue Injury. Circulation 2009; 120 (20): 2012-2024

[25] Schetter AJ, Heegaard NH, Harris CC, et al. Harris CC. Inflammation and cancer: interweaving microRNA, free radical, cytokine and p53 pathways. Carcinogenesis 2010; 31: $37-49$.

[26] Shepard CW, Finelli L, Alter MJ. Global epidemiology of hepatitis C virus infection. Lancet Infectious Disease 2005; 11 (9): 558-567.

[27] Su F-H, Shih-Ni C, Pei-Chun C, Fung-Chang S, Chien-Tien S, Chih-Ching Y. (2011). Association between chronic viral hepatitis infection and breast cancer risk: a nationwide population-based case-control study Bio Medical Center Cancer 11: 495.

[28] American Cancer Society (2015). Cancer Facts and Figures. Atlanta, Ga 2015

[29] Edge SB, Byrd DR, Compton CC, Fritz AG, Greene FG, Trotti A. AJCC Cancer Staging Manual 7. New York: Springer; 2010.

[30] Blaser MJ, Understanding Microbe-Induced Cancers. Cancer Preview Research 2008; 1: 15

[31] Blaser MJ, Kirschner D The equilibria that permit bacterial persistence in human hosts. Nature 2007; 449: 843-9

[32] Blaser MJ, Nomura A, Lee J, Stemmerman GN, Perez-Perez GI. Early life family structure and microbially-induced cancer risk. PLoS Med 2007; 4: 53-58.

[33] Chang YJ, Wu MS, Lin JT, Pestell RG, Blaser MJ, Chen CC. Mechanisms for Helicobacter pylori CagA-induced cyclin D1 expression that affect cell cycle. Cell Microbiology 2006 8: $1740-52$.

[34] Paschos K, Allday MJ. Epigenetic reprogramming of host genes in viral and microbial pathogenesis. Trends in Microbiology 2010; 18: 439-447.

[35] Jenner RG, Young RA. Insights into host responses against pathogens from transcriptional profiling. Nature Review Microbiology 2005; 3: 281-294.

[36] Bierne H, Mélanie H, Pascale C. (2012). Epigenetics and Bacterial Infections. Cold Spring Harb Perspective Medicine 2012; 2: a010272.

[37] Ribet D, Cossart P. (2010). SUMOylation and bacterial pathogens. Virulence 6: 532-534.

[38] Perrett CA, Lin DY, Zhou D. Interactions of bacterial proteins with host eukaryotic ubiquitin pathways. Frontier Microbiology 2011; 2: 143. 